\title{
THE END OF IGNORANCE?
}

\author{
Almantas SAMALAVIČIUS
}

Architecture's relation to its environment, be it built or natural, has always been somewhat ambiguous except perhaps during the period that we now label as pre-historical. Then human settlements were too closely tied to their environment to generate the sorts of problems that came with the development of civilization. But complicated and pressing problems accompanied that development, and, especially, the rise of modernity. Well-known consequences and side-effects of modernity's avatars, industrialization and urbanization, rapidly and irreversibly destroyed the former balance between the country and the city. The economic and social forces that triggered unprecedented growth of urban populations, first in Nineteenth-century Europe, and eventually all over the globe, determined the character of urban development in the last century no less decisively than in the dawn of the industrial era. More than half of the world's population is now living in cities despite an uneven distribution of wealth and power between the globe's north and south. The tendency of people to move to cities and urban clusters will definitely continue, spectacularly affecting and even drastically changing the present status quo and accordingly creating new problems and the search for solutions worldwide.

Since their origins, cities have always been places of consumption but in no prior historical epoch has consumption been the main driving force of society. The environmental impacts are clear. There is undeniable evidence that the world's natural resources have been largely exhausted or that their extraction has severely declined and become technologically much more complicated, more capital demanding and energy consuming. These alarming tendencies were outlined more than four decades ago by the authors of the clairvoyant Limits to Growth, and have been acknowledged and documented in a large number of recent studies such as The End of Growth by Richard Heinberg - to mention one among many insightful glimpses into our present and nearest future. The dominating form of our social life and its underlying current economic regime - call it late or senile capitalism or by any other name - has quickly triumphed all over the world since the failure and spectacular collapse of some of the last century's social utopias that developed into the nightmares of Nazism and Communism. Now, no more than two decades after the at-first-celebrated and now almost infamous "end of history", one has to acknowledge that our current social and economic forms are deeply flawed and in urgent need of reform.

Architecture and urban environments are not only the creations of universal human experience, technological knowledge, wisdom and self-awareness that developed in various phases of pre-industrial society. They are also the products of each historical epoch, its technological advances and particular intellectual milieu. The modern architecture and city building that evolved with the spread of industrialization and urbanization and the new concentrations and configurations of capital represents a huge break from previous epochs. Our technological knowledge has vastly expanded and we have witnessed a growing expansion of our needs for urban milieu, energy supplies, transportation, communication, commodities and services. By clinging to the idea of never-ending progress, modernity has sustained its central beliefs with the growth of technological know-how, the proliferation of building materials and technologically expanded capacities to extract cheap fossil fuels. I have observed urban development while teaching, researching or simply traveling in several continents during recent decades. While visiting London, Chicago, Tokyo, Seoul, Bangkok or 
Kuala Lumpur - to name just a few of the sprawling mega-cities on the globe's north and south - I have been struck by the persistent continuity of a phenomenon that was insightfully articulated by E. F. Schumacher, the renowned god-father of alternative economics, whose vision of truly human economics has given rise to a diffused international movement. Nonetheless, it seems that we still live in what he described as "the age of the Reign of Quantity", which haunted the nineteenth century when the industrial mode of production took command. This is particularly evident in the widespread influence of the ideas and practices of Le Corbusier and his followers in the last century. As Eamonn Canniffe has noted in his Ethic: Design in the Contemporary City: "The contemporary situation in urban design is in many ways still in thrall to the wholesale acceptance of Corbusian dogma in the period immediately succeeding the Second World War. Replacing the ground-hugging forms of the traditional city with the tower block and the urban motorway was a design strategy which was enthusiastically implemented across the developed world and beyond." Corbusier's legacy still persists, and deserves much more ethical scrutiny, and in general more re-consideration and assessment, if the course of urban planning and design processes is to undergo any significant change.

Visible urban signs and symbols of that era persist on their own, even though they are informed by the mentality and psychology of the industrial age and by naïve and narrow beliefs about the self-generating powers of progress, global welfare, availability of cheap energy resources and safe exploitation of the natural environment. Despite its evident defects, the numbers of misguided believers in this stale quasi-religious ideology are legion. Fortunately, wise and informed research into the future is now increasingly available, exemplified by the insightful recent studies in 2052: A Global Forecast for the Next Forty Years by Jorgen Randers (Randers is the one of the surviving authors of an epoch-making book Limits to Growth) or take a glimpse at The Ecotechnic Future edited by Michael Greer. These studies convincingly demonstrate that we are urgently in need of a breakthrough, first and foremost in our mental attitudes and with respect to some stubbornly persistent assumptions, and finally in our ways of acting. All this seems to be well-known, and yet surprisingly little has happened in terms of global politics despite the dissemination and proliferation of academic and journalistic jargon full of vocabulary entries, such as 'environmentalism,' 'sustainability,' 'sustainable cities' or 'green urbanism.'
Throughout the modern era - the period that generated a lot of self-reflection on the role and concepts of culture, civilization, humanity and the environment of human beings - there has been surprisingly little interest in architecture's and urbanism's relations to morality or ethics. The dominant professional discourses in architecture and urbanism have largely kept moral issues at a safe distance, as if they were contagious. Luckily, some pioneering and isolated intellectual endeavours like Geoffrey Scott's Architecture and Humanism of 1914 or more lately David Watkin's Morality and Architecture (1977) have during recent decades been followed by a growing volume of scholarship that takes ethical aspects of architectural practice, city building and its consequences more seriously than ever before. Volumes of interesting and important scholarly literature written or compiled and edited by Gregory Caicco, Warwick Fox, William M. Taylor, Thomas Fisher, Luis Pelletier and Alberto PerezGomez, Tom Spector, Mohsen Mostafavi - I mention only those few titles that have in recent years happened to enter my own architectural and urban bookscape as well as other recent writings indicate a growing awareness of the importance of ethical issues in and to architecture and more generally to human relations with both natural and built environments.

A sceptic may be inclined to argue that developments in academic vocabularies are in themselves of little importance. However, less sceptical individuals, including myself, may believe that we are in constant need of interpreting and re-interpreting the realities of our time, which may require a transformation of vocabularies; the ways we act largely depend on how we see and interpret the world.

In the realm of philosophical inquiry, there seems to be no universally agreed upon account of the nature and foundations of ethics and morality; consequently different schools of thought have been following a variety of traditions in thinking about human relationship with built and natural environments. Moreover, the global intellectual climate of recent decades - especially the rise of various forms of philosophical relativism and its suspicion of any universal truths or so-called grand narratives - seems to have created new problems. Defining what is ethical or unethical has in many cases become a murky endeavour or even a somewhat risky business, as attempts toward generalizations or universalizations came to be regarded as class-oriented, politically-biased or hegemonic. Consequently, some proposed definitions are imprecise and almost phantom-like. Take for example a claim found in The Journal of Business Ethics to the effect that ethics has 
to do fundamentally with "all human action aimed at securing a good life..." But before we can discuss what actions are aimed at securing a good life we must be able to give an account of 'a good life for humans', i.e. willingly or unwillingly we need to agree on the meaning and purpose of human existence and human actions. And this brings us back to the issue of truths that aspire to the status of universals - a dimension that has been and continues to be largely ignored in our current culture of scientism and relativism.

This issue on the ethical aspects of architecture and the environment, co-edited with philosopher Norman Lillegard (to whom my sincere thanks are due) is a modest yet I hope timely attempt to further advance a discourse on the ethical bearings of architecture in relation to urban and natural environments, a kind of discourse that can hardly be described as having come of age. Instead of focusing on some narrow, specific or supremely technical issues of philosophical ethics in relation to architecture, however, the editors of the present issue have chosen to broaden the scope of the directions pursued by inviting scholars and practitioners who have already reflected upon these issues elsewhere to contribute their most recent scholarly inquiries into ethical aspects of architecture and environment in a broad sense.

A few remarks, then, on the submissions to this issue: the article by Thomas Fisher deals with the question of a human right to architecture, a question that has already gained currency in theoretical discussions of architecture. In one of our previous issues, Peter Marcuse discussed people's rights to the city; in this issue Thomas Fisher raises a number of important questions about people's right to architecture, the answers to which define whether we remain human or think and act as neutral entities. Let me add that the atrocities of the last century committed by those who were reacting to human issues from an exclusively technical viewpoint should give us a lesson that can be applied to how we understand the role and place of human shelter in individual and social relations. In his article, Tom Spector urges us to reconsider publicness, which he sets out to explore as an important architectural value. Spector argues that the concept of the public that originated on the eve of the modern era is misconceived and lacks elaboration, but is still full of room for thought and social action. Kenneth G. Madsen and Nikos A. Salingaros discuss a neglected and rather dangerous issue - the lack of an essential ethical quality - honesty, among practitioners of the architectural profession. It might be added that the close connections between architects, urban planners, politicians, developers, builders and the real estate industry are often exempted from ethical scrutiny. Those who dare to offer such criticisms might want to keep in mind the advice once given by the late Denys Sutton to David Watkin after the publication of the latter's book on morality's relations to architecture - they both "should perhaps hire a bodyguard or even slip across the frontier" - given that their critique of current unethical conditions among members of this respectable profession was so open, dissident and deeply penetrating. Norman Lillegard steps back into recent history to examine the infamous case of Albert Speer, whose moral failings, some have claimed, were primarily failings qua architect. Though this claim seems dubitable, there might nonetheless be some specific ethical import in the works and workings of architects, just as much now as in the context of not-so-old history. Samir Younes examines the relationship between natural and built environments, i.e. the city, and calls for what he refers to as a co-evolutionary project that might help us to reconsider numerous pressing problems of our day in a new light. Finally, philosopher and visual artist Steven Schroeder articulates a call for what he describes as an "architecture of ethics" - another side of the ethic's coin. An insightful and thought-provoking review of Leon Krier's new edition of his monumental study of Albert Speer's architecture submitted by Samir Younes may force us to rethink some of our ideas about the relations between architecture, power, politics and the foundations of artistic work. I do hope these sharp, critical and insightful articles will receive not only a careful reading but will also prompt a dialogue, a continuous discussion that will challenge many of the assumptions that were formed during the last century about architecture, urbanism, natural environments and human beings. This issue is offered in the hope that we can still do something to create a better future even in a time, such as ours, that is full of global confusion and controversy. Finally, I would like to thank all the authors who accepted the editors' invitation to contribute to this issue. 